\title{
Red and fallow deer determine the density of Ixodes ricinus nymphs containing Anaplasma phagocytophilum
}

\author{
Katsuhisa Takumi ${ }^{1 *}$, Tim R. Hofmeester ${ }^{2}$ and Hein Sprong ${ }^{1}$
}

\begin{abstract}
Background: The density of Ixodes ricinus nymphs infected with Anaplasma phagocytophilum is one of the parameters that determines the risk for humans and domesticated animals to contract anaplasmosis. For this, I. ricinus larvae need to take a bloodmeal from free-ranging ungulates, which are competent hosts for A. phagocytophilum.

Methods: Here, we compared the contribution of four free-ranging ungulate species, red deer (Cervus elaphus), fallow deer (Dama dama), roe deer (Capreolus capreolus), and wild boar (Sus scrofa), to A. phagocytophilum infections in nymphs. We used a combination of camera and live trapping to quantify the relative availability of vertebrate hosts to questing ticks in 19 Dutch forest sites. Additionally, we collected questing I. ricinus nymphs and tested these for the presence of A. phagocytophilum. Furthermore, we explored two potential mechanisms that could explain differences between species: (i) differences in larval burden, which we based on data from published studies, and (ii) differences in associations with other, non-competent hosts.
\end{abstract}

Results: Principal component analysis indicated that the density of A. phagocytophilum-infected nymphs (DIN) was higher in forest sites with high availability of red and fallow deer, and to a lesser degree roe deer. Initial results suggest that these differences are not a result of differences in larval burden, but rather differences in associations with other species or other ecological factors.

Conclusions: These results indicate that the risk for contracting anaplasmosis in The Netherlands is likely highest in the few areas where red and fallow deer are present. Future studies are needed to explore the mechanisms behind this association.

\section{Background}

Anaplasma phagocytophilum is the causative agent of human granulocytic anaplasmosis (HGA), and it also causes disease and economic losses in domesticated animals [1-3]. The first human case in Europe was reported in 1995. Since then, HGA cases have only been occasionally reported throughout Europe [4]. It is unclear to

\footnotetext{
*Correspondence: katsuhisa.takumi@rivm.nl

${ }^{1}$ Centre for Zoonoses and Environmental Microbiology Centre

for Infectious Disease Control, National Institute for Public Health and the Environment (RIVM), Bilthoven, The Netherlands

Full list of author information is available at the end of the article
}

what extent HGA poses a health burden in Europe: epidemiological data on the disease incidence and disease burden are either incomplete or lacking from most European countries [2]. The non-specificity of the reported symptoms, poor diagnostic tools, and lack of awareness of public health professionals may also complicate these estimations [5]. Anaplasma phagocytophilum is transmitted by the bite of an infected tick $[6,7]$. The main vector in Europe is Ixodes ricinus, which also transmits Borrelia burgdorferi (s.l.), the causative agent of Lyme borreliosis, and several other pathogens [8]. The geographic spread and density of $I$. ricinus infected with $A$. phagocytophilum are important determinants of the disease risk $[9,10]$. original author(s) and the source, provide a link to the Creative Commons licence, and indicate if changes were made. The images or other third party material in this article are included in the article's Creative Commons licence, unless indicated otherwise in a credit line to the material. If material is not included in the article's Creative Commons licence and your intended use is not permitted by statutory regulation or exceeds the permitted use, you will need to obtain permission directly from the copyright holder. To view a copy of this licence, visit http://creativecommons.org/licenses/by/4.0/. The Creative Commons Public Domain Dedication waiver (http://creativeco mmons.org/publicdomain/zero/1.0/) applies to the data made available in this article, unless otherwise stated in a credit line to the data. 
Anaplasma phagocytophilum seems to appear in all countries across Europe with infection prevalence in nymphs (NIP) varying between and within countries from 0 to $25 \%$ [1]. Understanding which factors determine the spatial and temporal distribution of $I$. ricinus infected with $A$. phagocytophilum is needed for risk assessments and for formulating possible intervention strategies.

Variations in the density of questing I. ricinus infected with $A$. phagocytophilum (DIN) have partly been attributed to environmental factors such as differences in weather conditions [11, 12], habitat characteristics [13], as well as vertebrate communities [14]. Whereas small mammals and birds are considered to feed the majority of immature $I$. ricinus, ungulates act as their main propagation host [15]. It is, however, still unclear which host species form the main reservoir for A. phagocytophilum and therefore contribute most to the density of infected ticks. Anaplasma phagocytophilum has been found to infect many vertebrate species [1], but its genetic diversity indicates that there are multiple genetic variants, or ecotypes, with distinct but overlapping transmission cycles, pathogenicity, and geographical origin [16-18]. A variety of wildlife species, like red deer (Cervus elaphus), fallow deer (Dama dama), wild boar (Sus scrofa), and European hedgehog (Erinaceus europaeus), are harbouring A. phagocytophilum variants that can cause disease in humans and domesticated animals, whereas roe deer (Capreolus capreolus), rodents, and birds seem to carry genetic variants that have until now not been associated with human disease [17].

About two-thirds of tick bites reported in The Netherlands are $I$. ricinus nymphs [19]. Therefore, the density of questing nymphs infected with $A$. phagocytophilum (DIN) is an important ecological parameter that, together with the level of human exposure, determines tick-borne disease risk $[9,20]$. The DIN is calculated by multiplying the density of questing $I$. ricinus nymphs (DON) by nymphal infection prevalence (NIP). The transmission of $A$. phagocytophilum predominantly relies on horizontal transmission between ticks and vertebrate hosts and on transstadial transmission in its vectors, as vertical (transovarial) transmission has not been documented for I. ricinus. Therefore, an I. ricinus larva needs to take a bloodmeal from an infected vertebrate host to become an infected $I$. ricinus nymph. The availability of (infected) vertebrates to questing larvae generally drives the density of (infected) I. ricinus nymphs [14, 21, 22].

Using data from a cross-sectional study estimating the availability of hosts with camera and live traps in 19 Dutch forest sites, we quantified a moment when a questing tick encounters an ungulate; the probability of this event predicts both $I$. ricinus nymphal density and A. phagocytophilum DIN [14]. However, the reported association for A. phagocytophilum DIN left a relatively large proportion of the variation among sites unexplained, which could be because of the grouping of four ungulate species. The group of ungulates considered consisted of four species that differed in their ecology and potentially in their ability to be hosts for $I$. ricinus and $A$. phagocytophilum.

Here, we present a re-analysis of the $A$. phagocytophilum data from the cross-sectional study to disentangle the role of the four ungulate species in determining $A$. phagocytophilum DIN. We first applied a principal component analysis to the camera and live trapping data to test if availability of any of the four ungulate species or combinations of species was associated with $A$. phagocytophilum DIN. Second, we used simple mathematical models to explore two potential mechanisms that could explain differences between species: (i) differences in $I$. ricinus larval burden and (ii) potential associations of the different ungulate species with alternative incompetent host species.

\section{Methods \\ Cross-sectional study}

We made use of data from an extensive field survey that was carried out in 19 1-ha sites located in forested areas in The Netherlands in 2013 and 2014. Data were collected on the density of questing $I$. ricinus (blanket dragging), vertebrate communities (camera and live trapping), and infection rates of tick-borne pathogens (qPCR detection). The sites, methodologies, and data have been described elsewhere as well as a series of detailed analyses [14, 22-24].

\section{Host attribution}

We arranged the encounter probabilities for all forest sites $(n=19)$ and vertebrate species $(n=32)$ into a matrix $\mathbf{A} \in \mathbb{R}^{19 \times 32}$ having 19 rows and 32 columns. We further arranged $A$. phagocytophilum DIN into a vector $b$ matching the order of the forest sites along the rows of $\mathbf{A}$. To attribute $A$. phagocytophilum DIN to an assemblage of 32 vertebrate species, we factored the matrix $\mathbf{A}$ into two orthogonal matrices

$$
\begin{gathered}
\mathbf{U}=\left[u_{1}, u_{2}, \ldots, u_{19}\right] \in \mathbb{R}^{19 \times 19} \text { and } \\
\mathbf{V}=\left[v_{1}, v_{2}, \ldots, v_{32}\right] \in \mathbb{R}^{32 \times 32}
\end{gathered}
$$

and a diagonal matrix $\Sigma \in \mathbb{R}^{19 \times 32}$ with the singular values $\sigma_{1} \geq \sigma_{2} \cdots \geq \sigma_{19} \geq 0$ and the remaining entries equal to zero. Theorem 2.5.2 [25] proves that $\mathbf{A}=\mathbf{U} \boldsymbol{\Sigma} \mathbf{V}^{T}$. The column vectors $u_{i}$ and $v_{i}$ are principal components, also known as singular vectors. 
The A. phagocytophilum DIN increased at each forest site because of the first principal components by the amount (Theorem 5.5.1 [25])

$$
\frac{u_{1} \cdot b}{\sigma_{1}} \mathbf{A} v_{1} \in \mathbb{R}^{19}
$$

We attributed Eq. (1) to roe deer because the highest contribution from the first principal component $v_{1}$ comes from roe deer. Next, we applied the theorem again to quantify the inputs from the lower principal components $v_{2}, v_{3} \ldots$,

$$
y=\sum_{i=2}^{8} \frac{u_{i} \cdot b}{\sigma_{i}} \mathbf{A} v_{i} \in \mathbb{R}^{19} .
$$

Lower components $v_{9} \ldots v_{19}$ are ignored because the tail sum $\sum_{i=9}^{19} \sigma_{i}^{2}$ is negligible (2.43\%) compared to the whole cumulative sum $\sum_{i=2}^{19} \sigma_{i}^{2}$. Next, we define

$$
\begin{aligned}
& y^{+}=\max (y, 0), \\
& y^{-}=\max (-y, 0) .
\end{aligned}
$$

Intuitively, we clipped the solution $y$ into the positive part $y^{+}$and the negative part $y^{-}$. We attributed Eq. (2) to fallow deer, red deer, and wild boar because the highest contributions from the second principal component $v_{2}$ and the third $v_{3}$ come from these species.

\section{Larval tick burden on ungulates}

Ungulates generally contribute relatively little as hosts for feeding I. ricinus larvae compared to rodents and birds [15]. Nevertheless, as important hosts for A. phagocytophilum, ungulates might feed a significant fraction of larvae that later become $A$. phagocytophilum-infected nymphs. Thus, differences in larval burden between ungulate species could contribute to differences in their importance as hosts contributing to A. phagocytophilum DIN. To explore this, we compiled data from published studies that collected I. ricinus larvae attached to individual ungulates (see Additional file 1: Table S1). We extracted species, the number of checked animals, and the number of $I$. ricinus larvae attached to the animals. We fit the negative binomial model (log-link) to the number of larval ticks using the number of animals and the species as predicting variables. We tested the significance of the species predicting variable by performing the likelihood ratio test.

\section{Associations with other woodland species}

We explored whether differences between species could be explained by associations of the different ungulate species with the availability of other host species. Here, two species might appear related because of the probability condition (the sum of rates over the host species must equal to one). To remove this potential bias, we performed the following analysis using the encounter rates instead of the encounter probability. For this, we calculated the Pearson correlation in the encounter rate for each ungulate species with each other woodland species. We fit the binomial model (logit link) to the frequency of positive and negative correlation values using the ungulate species as a predicting variable. We tested the significance of the predicting variable by performing the likelihood ratio test.

Absent species interaction, correlation values should be close to zero, and the deviation from the expected value zero should be symmetric. It is possible to calculate the probability of observing as many or more negative correlation values as actually observed in the vertebrate community,

$$
\frac{1}{2^{-n}} \sum_{j=k}^{n}\left(\begin{array}{l}
n \\
j
\end{array}\right) .
$$

This is a partial sum of binomial probability densities where a correlation value is negative with probability $\frac{1}{2}$. The vertebrate community counts $n$ members. The number of negative correlation values observed in the vertebrate community equals $k$. All computations were implemented using the $\mathrm{R}$ language [26].

\section{Results}

\section{Tick densities}

We collected a total of 16,568 I. ricinus nymphs at the 19 forest sites. Most of the collected nymphs $(n=13,967)$ were tested for the presence of $A$. phagocytophilum DNA resulting in an overall infection prevalence of $3.3 \%$ (456 infected nymphs), which we used to calculate the density of infected nymphal ticks (DIN). Using correlation analyses, we detected a significant correlation between the number of positive nymphs, NIP, and DIN (Table 1). DIN of A. phagocytophilum lacked a clear correlation with the density of nymphal ticks (DON; Table 1).

\section{Host attribution}

The encounter of an I. ricinus larva with a woodland species is a critical event to a successful A. phagocytophilum transmission. We quantified the probability of an encounter event based on the information collected using camera- and live-traps in the 19 forest sites (see Additional file 1: Fig S1). We found that the majority of the observed A. phagocytophilum DIN can be attributed to the encounter probabilities of fallow deer, red deer, and wild boar (Fig. 1), based on the correlation of the attributed DIN to the three free-ranging ungulate species 
Table 1 Density of nymphs infected with A. phagocytophilum $(\mathrm{DIN})$ is unrelated with the density of nymphs (DON)

\begin{tabular}{llllll}
\hline & DON & Test & Positive & NIP & DIN \\
\hline DON & & & & \\
Test & 0.7 & & & \\
Positive & 0.26 & 0.48 & & \\
NIP & 0.11 & 0.22 & 0.93 & \\
DIN & 0.34 & 0.41 & 0.94 & 0.91 \\
\hline
\end{tabular}

Table entries are Pearson correlations calculated using Additional file 1: Table S2. Numerals are italicized when the $p$-value is $<0.05$. DON: Density of questing Ixodes ricinus nymphs. Test: Number of questing Ixodes ricinus nymphs tested for the presence of Anaplasma phagocytophilum. Positive: Number of Anaplasma phagocytophilum presence in questing lxodes ricinus nymphs

NIP Positive divided by test, DIN density of infected Ixodes ricinus nymphs.

(Fig. 2). We, however, did not find a correlation with the attributed DIN to roe deer (Table 2).

\section{Larval tick burden on ungulate species}

Based on the data extracted from 12 studies in the literature [27-38], which together report 24,794 I. ricinus larvae attached to 1860 individual ungulates in
6 European countries, we found no support for the hypothesis that differences in $I$. ricinus larval burden could have caused the differences in association with $A$. phagocytophilum DIN among the four ungulate species (Table 3).

\section{Reducing availability of woodland species}

The encounter rate of roe deer correlated negatively with the encounter rates of 14 woodland species and positively with 17 (Table 4). The probability of exceeding the number of negative correlations is 0.81 . The other free-ranging ungulates showed a different pattern: Encounter rates of red deer correlated negatively with encounter rates of 23 woodland species, fallow deer with 26 woodland species, and wild boar with 23 woodland species (Table 4). Consequently, we found a clear difference among these ungulate species in the frequency of negative correlations with other woodland species $(p$-value $=0.010623$, deviance $=11.2140483$, d.f. $=3)$. The probability of exceeding the number of negative correlation is low: red deer: 0.01 ; fallow deer: 0.00027 : wild boar: 0.01 .

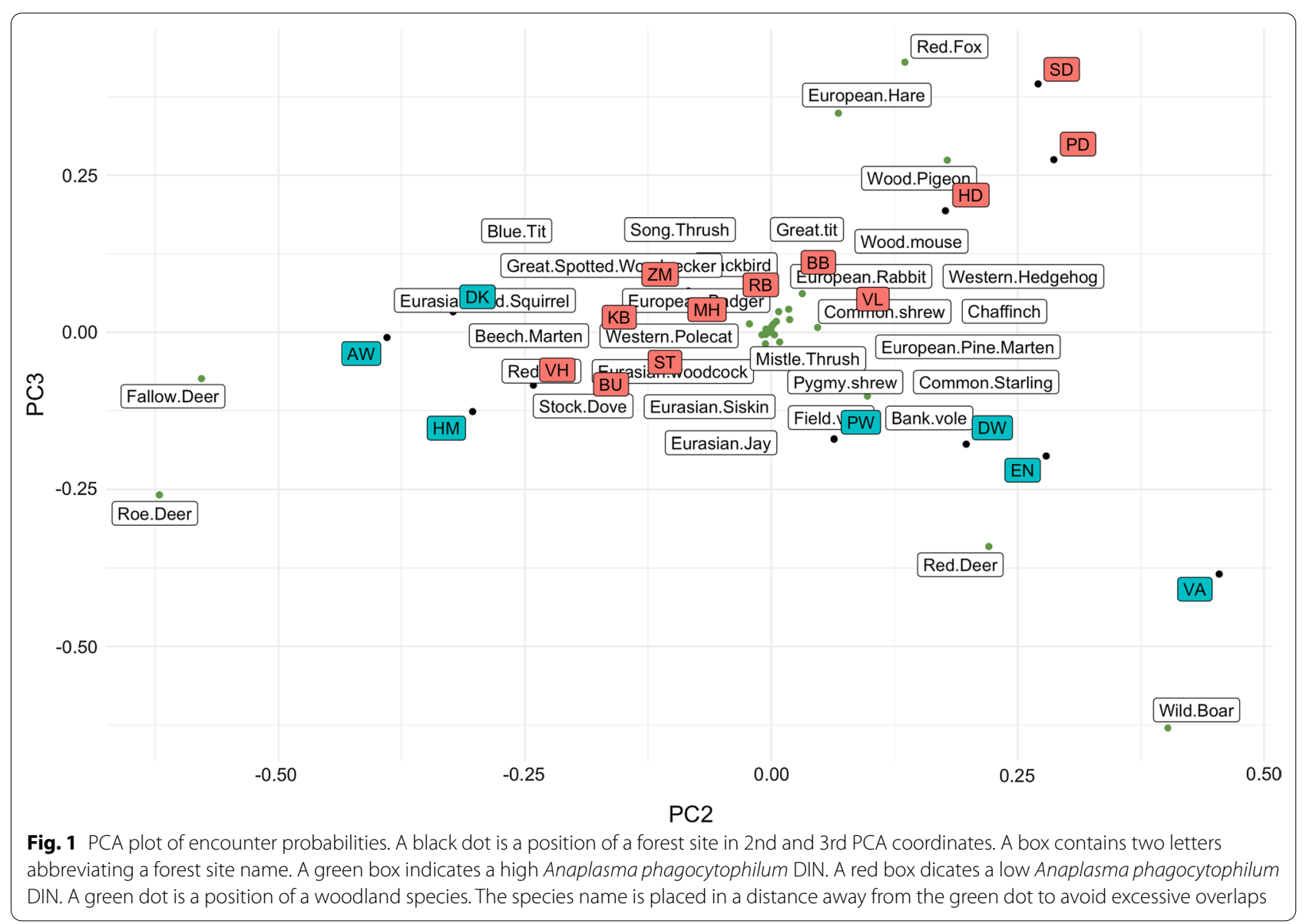




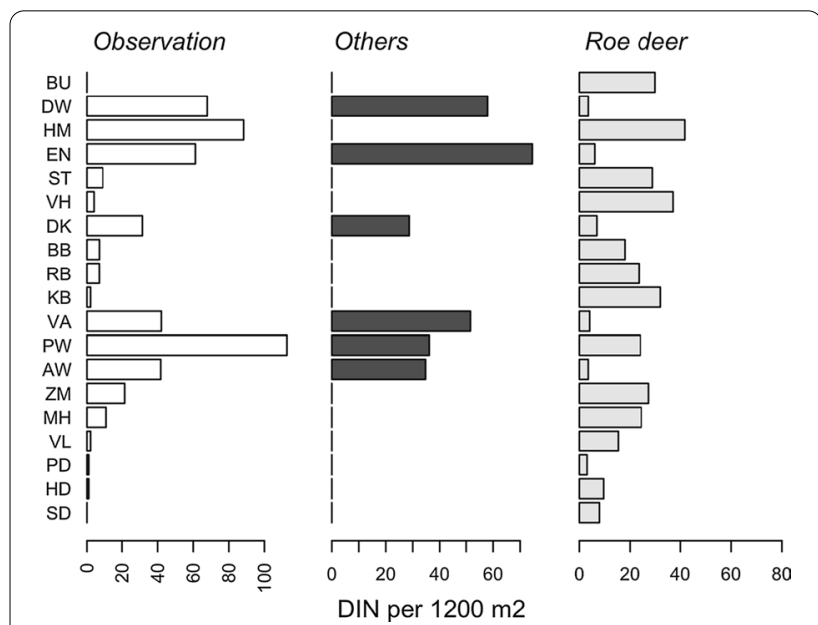

Fig. 2 The three free-ranging ungulates except roe deer support Anaplasma phagocytophilum DIN. Observed Anaplasma phagocytophilum DIN was calculated by multiplying the density of questing /xodes ricinus nymphs by the Anaplasma phagocytophilum NIP. Bar heights in the middle panel (others referring to fallow deer, red deer, and wild boar) were calculated using Eq. (2). Bar heights in the right panel were calculated using Eq. (1)

Table 2 Observed Anaplasma phagocytophilum DIN lacks a correlation with roe deer and correlates with the other feeranging ungulates

\begin{tabular}{|c|c|c|c|}
\hline & Observation & Others & Roe deer \\
\hline \multicolumn{4}{|c|}{ Observation } \\
\hline Others & 0.64 & & \\
\hline Roe deer & -0.02 & -0.56 & \\
\hline
\end{tabular}

\section{Discussion}

Re-analysing a cross-sectional study of observed A. phagocytophilum DIN at 19 Dutch forest sites [14], we show that most of the variation in DIN can be explained by differences in encounter probability among ungulates species that were not taken into account in the original analysis. We found a clear association of $A$. phagocytophilum DIN with the encounter probabilities of fallow deer, red deer, and wild boar. A first exploration of two potential mechanisms that could cause the difference among ungulate species in their contribution to the DIN indicated that negative
Table 4 Frequency of positive and negative correlations in encounter rates with 32 woodland species

\begin{tabular}{lll}
\hline & Positive & Negative \\
\hline Roe deer & 18 & 14 \\
Fallow deer & 6 & 26 \\
Red deer & 9 & 23 \\
Wild boar & 9 & 23 \\
\hline
\end{tabular}

A cell displays a number of woodland species having a positive (or negative) correlation with the ungulate species. Additional file 1:Table $\mathrm{S} 3$ displays the data.

association of fallow deer, red deer, and wild boar with the encounter rate of other woodland species is a likely candidate for the found differences. In contrast, we did not find support for an explanation based on differences in $I$. ricinus larval burden. In The Netherlands, fallow deer, red deer, and wild boar only occur in a few specific areas (Fig. 3). Therefore, we cannot rule out if found associations with other woodland species are a result of ecological (interspecies) interactions or species associations with different habitats and wildlife management. It is, however, clear that forested areas where fallow deer, red deer, or wild boar occur likely have the highest risk for humans and domesticated animals to be exposed to $A$. phagocytophilum though tick bites. Targeted health campaigns to increase the awareness amongst health professionals might help to identify HGA cases and may further be used for stimulation of preventive measures.

\section{Previous research linking species difference to Anaplasma phagocytophilum}

We did not find differences among ungulates in their $I$. ricinus larval burden based on published studies. However, the number of studies was limited $(n=12)$, especially for some species $(n=1$ for fallow deer and wild boar). Thus, the lack of differences is likely a result of large variation in larval burdens and limited sample sizes, especially as studies comparing I. ricinus burden among different ungulate species in single study sites did find differences among species [27, 28]. This indicates that there is a need for more comparative studies investigating differences in the $I$. ricinus burden of the different ungulates related to differences in infection prevalence with $A$. phagocytophilum in both hosts and feeding ticks.

Table 3 Analysis of larval ticks on four ungulate species

\begin{tabular}{llllll}
\hline Model & Theta & Resid. df & 2 xlog-lik. & Test & df \\
\hline Samples & 0.289 & 18 & -293.764 & & LR stat. \\
Samples + Species & 0.317 & 15 & -291.179 & 1 vs 2 & 3 \\
\hline
\end{tabular}

Additional file 1: Table S1 displays the data. 


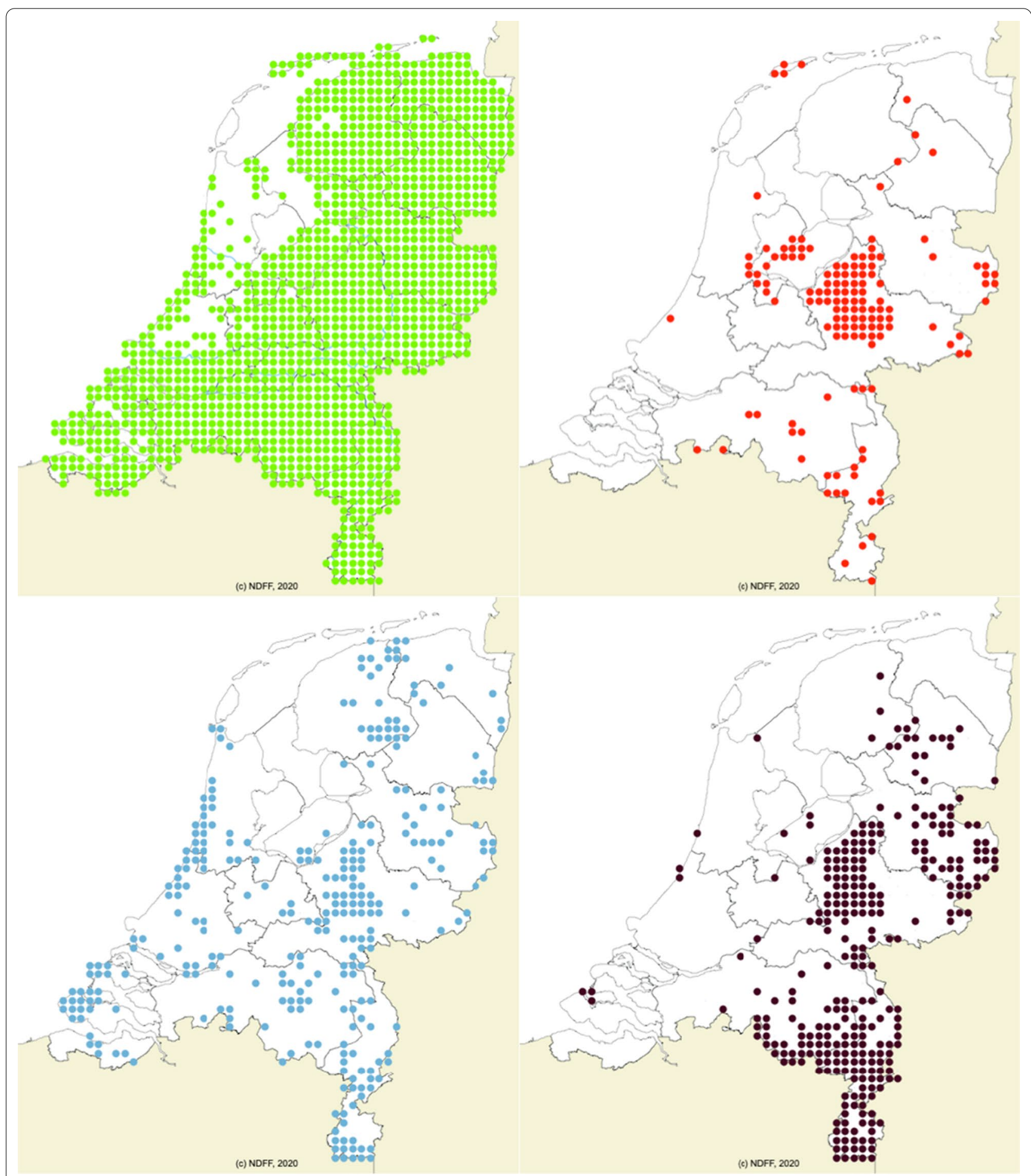

Fig. 3 Ungulate presence: The Netherlands 2000-2020 (Source: https://www.verspreidingsatlas.nl Green: roe deer. Red: red deer. Blue: fallow deer. Black: wild boar)

We found a negative association in the encounter rates of fallow deer, red deer, and wild boar with the encounter rates of other woodland species, which could be caused by both ecological interactions and management practices. Contrary to roe deer, these three species have a very limited distribution in The 
Netherlands occurring mainly in the dunes along the coast (fallow deer) and on a large forested area in the middle of The Netherlands called the Veluwe (Fig. 3). This restricted distribution is completely due to present and past wildlife management [39]. Both of these areas are characterized by relatively high sandy soils resulting in relatively low productivity [40]. As a result, both the coastal dunes and the Veluwe harbour a limited number of species, which could explain the negative associations we found. Simultaneously, there could be additional interspecific interactions explaining some of our results. An experimental study [41] reported evidence for cascading effects by ungulates on a temperate forest ecosystem. Experimentally excluding fallow deer, roe deer, red deer, wild boar, and mouflon (Ovis orientalis) from a temperate forest ecosystem in the Veluwe decreased the density of soil grains and increased litter depth, invertebrate biomass, and rodent activity. Future studies are needed to test for the contribution of either mechanism on the found negative associations.

The bacterium $A$. phagocytophilum is divided into four ecotypes based on the groEL sequences and the host association [16]. These ecotypes differ in their zoonotic potential, with ecotype I being able to cause HGA in humans and anaplasmosis in domesticated animals. This is concerning, as red and fallow deer are considered host species for ecotype I [16]. Thus, the peaks in A. phagocytophilum DIN in areas with a high encounter probability with fallow deer and red deer indicate that these nymphs are likely infected with ecotype I. In contrast, roe deer are considered hosts for the non-zoonotic ecotype II. As the geographic distribution of fallow and red deer in The Netherlands (Fig. 3) is far more restricted than the distribution of roe deer, this would imply that the risk of acquiring HGA is largely restricted to areas where red/ fallow deer are present. This might be one of explanations for the low incidence of (reported) HGA cases.

Strikingly, we did not find a correlation of $A$. phagocytophilum DIN at the forest sites with the encounter probability of a questing nymph with roe deer (Fig. 2). This contrasts with the finding that the density of questing nymphal ticks in the same forest sites correlated with the encounter probability [14]. Thus, we detected in this cross-sectional study some degree of impedance in the $A$. phagocytophilum life cycle and no evidence of any impedance in the tick life cycle at the forest sites where roe deer is the predominant competent species. This appears to be a common situation in the Dutch forest areas with some exceptions. We observed a high $A$. phagocytophilum DIN at the forest site Halfmijl (HM) (Fig. 2). Only roe deer and none of the other free-ranging ungulates were captured by the camera trapping at the forest site.
There are additional aspects of $A$. phagocytophilum transmission, which could influence $A$. phagocytophilum DIN in theory. Questing nymphs may have been infected by $A$. phagocytophilum while co-feeding as an uninfected larva next to infected nymphs on the same deer. Next, not all variants of $A$. phagocytophilum might persist to the same extent during the off-host period. The low DIN associating with roe deer in our dataset might be due to a lower persistence of Ecotype II in I. ricinus during the off-host period. With regard to co-infection, A. phagocytophilum causes a chronic/systemic infection in deer, implying that the subsequent larvae feeding on deer will become infected [16]. The latter will be substantially more than the few larvae feeding at the same time with an infected nymph. With regard to differential persistence, a study of $A$. phagocytophilum Ecotypes in Central Europe did not find less Ecotype II than Ecotype I in questing $I$. ricinus nymphs originating from a site in the presence of roe deer [13]. For these reasons, co-feeding and differential persistence were omitted from the analyses.

\section{Conclusion}

In conclusion, our re-analysis of the cross-sectional study suggests that the risk of contracting anaplasmosis in the forest with fallow deer, red deer, and wild boar is high compared to the remaining forest sites where roe deer is the predominant competent host. Geographical distribution of deer species in The Netherlands implies that the risk of acquiring HGA is largely restricted to areas where red/fallow deer are present. Additional studies are required to test the inference based on our associative study.

\section{Abbreviations}

HGA: Human granulocytic anaplasmosis; DON: Density of questing Ixodes ricinus nymphs; DIN: Density of infected nymphs; NIP: Infection prevalence in nymphs.

\section{Supplementary Information}

The online version contains supplementary material available at https://doi. org/10.1186/s13071-020-04567-4.

Additional file 1. Additional figure and tables.

\section{Acknowledgements}

Not applicable.

\section{Authors' contributions}

KT analysed and interpreted the data regarding the vertebrate, tick, and the tick-borne pathogen and wrote the manuscript. TH interpreted the analyses and was a major contributor in writing the manuscript. HS seeded the study, provided the funding, and reviewed the manuscript. All authors read and approved the final manuscript. 


\section{Funding}

This research was financially supported by the Dutch Ministry of Health, Welfare and Sport (VWS), by a Grant from the ZonMw (project number 50-52200-98-313, Ticking on Pandora's box) and a grant from the European Interreg North Sea Region program, as part of the NorthTick project.

\section{Availability of data and materials}

The datasets used and/or analysed during the current study are available from the corresponding author on reasonable request

\section{Ethics approval and consent to participate}

Not applicable.

\section{Consent for publication}

Not applicable.

\section{Competing interests}

The authors declare that they have no competing interests.

\section{Author details}

${ }^{1}$ Centre for Zoonoses and Environmental Microbiology Centre for Infectious Disease Control, National Institute for Public Health and the Environment (RIVM), Bilthoven, The Netherlands. ${ }^{2}$ Department of Wildlife Fish and Environmental Studies, Swedish University of Agricultural Sciences, Skogsmarksgränd 7, 90736 Umeå, Sweden.

Received: 15 October 2020 Accepted: 28 December 2020 Published online: 19 January 2021

\section{Reference}

1. S Stuen EG Granquist C Silaghi 2013 Anaplasma phagocytophilum-a widespread multi-host pathogen with highly adaptive strategies Front Cell Infect Microbiol. 331

2. IA Matei A Estrada-Peña SJ Cutler M Vayssier-Taussat L Varela-Castro A Potkonjak 2019 A review on the eco-epidemiology and clinical management of human granulocytic anaplasmosis and its agent in Europe Parasit Vectors. 12599

3. E Hovius A Bruin de L Schouls J Hovius N Dekker H Sprong 2018 A lifelong study of a pack Rhodesian ridgeback dogs reveals subclinical and clinical tick-borne Anaplasma phagocytophilum infections with possible reinfection or persistence Parasit Vectors. 11238

4. T Azagi D Hoornstra K Kremer JWR Hovius H Sprong 2020 Evaluation of disease causality of rare ixodes ricinus-borne infections in Europe Pathogens. 91

5. E Tijsse-Klasen MPG Koopmans H Sprong 2014 Tick-borne pathogen reversed and conventional discovery of disease Front Public Health. 273

6. JJ Fourie A Evans M Labuschagne D Crafford M Madder M Pollmeier 2019 Transmission of Anaplasma phagocytophilum (Foggie, 1949) by Ixodes ricinus (Linnaeus, 1758) ticks feeding on dogs and artificial membranes Parasit Vectors. 12136

7. NH Ogden ANJ Casey NP French Z Woldehiwet 2002 A review of studies on the transmission of Anaplasma phagocytophilum from sheep: implications for the force of infection in endemic cycles Exp Appl Acarol. 28195 202

8. H Sprong T Azagi D Hoornstra AM Nijhof S Knorr ME Baarsma 2018 Control of Lyme borreliosis and other Ixodes ricinus-borne diseases Parasit Vectors. 11145

9. TN Mather MC Nicholson EF Donnelly BT Matyas 1996 Entomologic index for human risk of Lyme disease. Am J Epidemiol. 14410661069

10. H Sprong A Hofhuis F Gassner W Takken F Jacobs AJH Vliet van 2012 Circumstantial evidence for an increase in the total number and activity of Borrelia-infected Ixodes ricinus in the Netherlands Parasit Vectors. 5294

11. EC Coipan S Jahfari M Fonville CB Maassen J Giessen van der W Takken 2013 Spatiotemporal dynamics of emerging pathogens in questing Ixodes ricinus Front Cell Infect Microbiol. 336

12. E Lejal M Marsot K Chalvet-Monfray J-F Cosson S Moutailler M VayssierTaussat 2019 A three-years assessment of Ixodes ricinus-borne pathogens in a French peri-urban forest Parasit Vectors. 12551
13. Z Hamšíková C Silaghi K Takumi I Rudolf K Gunár H Sprong 2019 Presence of roe deer affects the occurrence of Anaplasma phagocytophilum ecotypes in questing ixodes ricinus in different habitat types of central Europe Int J Environ Res Public Health. 161

14. KTakumi H Sprong TR Hofmeester 2019 Impact of vertebrate communities on Ixodes ricinus-borne disease risk in forest areas Parasit Vectors. 12 434

15. Hofmeester TR, Coipan EC, Wieren SE van, Prins HHT, Takken W, Sprong $H$. Few vertebrate species dominate the Borrelia burgdorferi s.l. life cycle. Environmental Research Letters. IOP Publishing; 2016;11:043001.

16. S Jahfari EC Coipan M Fonville AD Leeuwen van P Hengeveld D Heylen 2014 Circulation of four Anaplasma phagocytophilum ecotypes in Europe Parasit Vectors. 7365

17. RI Jaarsma H Sprong KTakumi M Kazimirova C Silaghi A Mysterud 2019 Anaplasma phagocytophilum evolves in geographical and biotic niches of vertebrates and ticks Parasit Vectors. 12328

18. DB Langenwalder S Schmidt C Silaghi J Skuballa N Pantchev IA Matei 2020 The absence of the drhm gene is not a marker for human-pathogenicity in European Anaplasma phagocytophilum strains Parasit Vectors. 13238

19. A Hofhuis J Kassteele van de H Sprong CC Wijngaard van den MG Harms M Fonville 2017 Predicting the risk of Lyme borreliosis after a tick bite, using a structural equation model PLoS ONE 12 e0181807

20. SE Randolph 2004 Tick ecology: processes and patterns behind the epidemiological risk posed by ixodid ticks as vectors Parasitology 129 Suppl S37 65

21. Al Krawczyk GLA Duijvendijk van A Swart D Heylen RI Jaarsma FHH Jacobs 2020 Effect of rodent density on tick and tick-borne pathogen populations: consequences for infectious disease risk Parasit Vectors. 13 34

22. Hofmeester TR, Jansen PA, Wijnen HJ, Coipan EC, Fonville M, Prins HHT, et al. Cascading effects of predator activity on tick-borne disease risk. Proc Biol Sci. 2017;284

23. TR Hofmeester H Sprong PA Jansen HHT Prins SE Wieren van 2017 Deer presence rather than abundance determines the population density of the sheep tick, Ixodes ricinus, in Dutch forests Parasit Vectors. 10433

24. Al Krawczyk JW Bakker CJM Koenraadt M Fonville K Takumi H Sprong 2020 Tripartite Interactions among Ixodiphagus hookeri Differential Interference with Transmission Cycles of Tick-Borne Pathogens. Pathogens xodes ricinus and Deer 9

25. GH Golub CF Loan Van 1996 Matrix computations 3 Johns Hopkins University Press USA

26. R Core Team. R: A language and environment for statistical computing. Vienna, Austria: R Foundation for Statistical Computing; 2015.

27. FCA Pacilly ME Benning F Jacobs J Leidekker H Sprong SEV Wieren 2014 Blood feeding on large grazers affects the transmission of Borrelia burgdorferi sensu lato by Ixodes ricinus Ticks Tick Borne Dis. 5810817

28. FR Matuschka M Heiler H Eiffert P Fischer H Lotter A Spielman 1993 Diversionary role of hoofed game in the transmission of Lyme disease spirochetes Am J Trop Med Hyg. 48693699

29. S Hornok G Horváth F Jongejan R Farkas 2012 lxodid ticks on ruminants, with on-host initiated moulting (apolysis) of Ixodes Haemaphysalis and Dermacentor larvae. Vet Parasitol. 187350353

30. A Mysterud L Qviller EL Meisingset H Viljugrein 2016 Parasite load and seasonal migration in red deer Oecologia 180401407

31. A Mysterud IL Hatlegjerde OJ Sørensen 2014 Attachment site selection of life stages of Ixodes ricinus ticks on a main large host in Europe, the red deer (Cervus elaphus) Parasit Vectors. 7510

32. K Handeland L Qviller T Vikøren H Viljugrein A Lillehaug RK Davidson 2013 Ixodes ricinus infestation in free-ranging cervids in Norway-a study based upon ear examinations of hunted animals Vet Parasitol. 195142 149

33. C Kiffner C Lödige M Alings TVor F Rühe 2010 Abundance estimation of Ixodes ticks (Acari: Ixodidae) on roe deer (Capreolus capreolus) Exp Appl Acarol. 527384

34. FJ Pato R Panadero L Vázquez CM López P Díaz E Vázquez 2013 Seroprevalence of Borrelia burgdorferi sensu lato in roe deer (Capreolus capreolus) from northwestern Spain J Zoo Wildl Med. 44660665

35. L Tälleklint TG Jaenson 1997 Infestation of mammals by Ixodes ricinus ticks (Acari: Ixodidae) in south-central Sweden Exp Appl Acarol. 21755771 
36. L Vázquez R Panadero V Dacal FJ Pato C López P Díaz 2011 Tick infestation (Acari: Ixodidae) in roe deer (Capreolus capreolus) from northwestern Spain: population dynamics and risk stratification Exp Appl Acarol. 53399 409

37. TVor C Kiffner P Hagedorn M Niedrig F Rühe 2010 Tick burden on European roe deer (Capreolus capreolus) Exp Appl Acarol. 51405417

38. N Król L Chitimia-Dobler G Dobler Y Karliuk S Birka A Obiegala 2020 Tick burden on European roe deer (Capreolus capreolus) from Saxony, Germany, and detection of tick-borne encephalitis virus in attached ticks Parasitol Res. 11913871392

39. van Wieren S, Groot Bruinderink G. Ungulates and their management in the netherlands. In: Apollonia M, Andersen R, Putman R, editors. European ungulates and their management in the 21th century. Cambridge University Press; 2010. pp. 165-83.
40. A Kooijman A Smit 2001 Grazing as a measure to reduce nutrient availability and plant productivity in acid dune grasslands and pine forests in the netherlands Ecol Eng 176377

41. Jl Ramirez PA Jansen J Ouden den L Moktan N Herdoiza L Poorter 2020 Above- and below-ground cascading effects of wild ungulates in temperate forests Ecosystems. Springer Science Business Media LLC

\section{Publisher's Note}

Springer Nature remains neutral with regard to jurisdictional claims in published maps and institutional affiliations.
Ready to submit your research? Choose BMC and benefit from:

- fast, convenient online submission

- thorough peer review by experienced researchers in your field

- rapid publication on acceptance

- support for research data, including large and complex data types

- gold Open Access which fosters wider collaboration and increased citations

- maximum visibility for your research: over 100M website views per year

At BMC, research is always in progress.

Learn more biomedcentral.com/submissions 